\title{
Optimal Placement of Series and Compound Compensators for Power Loss Minimization based on WPSO Algorithm
}

\author{
Ruba AL-Mula Humadi \\ Mechanical Engineering \\ Department \\ College of Engineering \\ Baghdad University/ Baghdad/Iraq
}

\begin{abstract}
This paper presents series and compound compensators that will be added to the power system in order to enhance the voltage stability during the increasing in power demand. In order to get the optimal location, size and the minimum power loss of these compensators a comparative study is made between the two types based on normal PSO and weighted PSO optimization methods. The proposed algorithm is applied on IEEE 30-bus test system and the simulations have been made in MATLAB R2013a software environment. The results show that the system performance is better with WPSO than PSO.
\end{abstract}

\section{Keywords}

Power flow, standard PSO, WPSO

\section{INTRODUCTION}

Series and shunt compensations are widely used in electrical power system to improve the voltage profile, increase the system load ability and minimize the power loss during excessive reactive loading conditions.

Series compensation is used to increase the available transfer capability while the shunt compensation is used to improve the voltage stability of the whole system. So the location, size and type of these devices are very important factors.

Hasan et. al.[1], studied the effects of series and shunt compensations on transmission line the analysis was applied to $380-154-66 \mathrm{kv}$ voltage levels of Turkish transmission system. Thyristor controlled series compensation (TCSC) was used to increase the available transfer capability.

Ulas et. al.[2], presented the effect of shunt and series compensations on system voltage profile and line losses for different load models. A simple model was built to develop these calculations and two different line models (one was the nominal $\pi$ circuit and the second was distributed line model) have been used in analyzing the effects of different load models on transmission system performance. The selection of shunt capacitor size is also affected by the voltage level.

Om and Sheesh [3], installed FACTS devices in the electric transmission network of Rajasthan Rajya Vidhyut Prasaran Nigam Ltd (RRVPNL) Indian power grid to improve the active and reactive power. A $132 \mathrm{KV}$ transmission line was used to transfer electric power from a $220 \mathrm{KV}$ GSS to a 132 KV GSS and was modeled in MATLAB/Simulink environment. The results were obtained for uncompensated system, compensated with HT Shunt Capacitor Banks and compensated system with SVC. After comparing the results the authors investigated that the system with SVC has less transmission line loss.

Some authors focused their research about the minimization of power loss by using swarm intelligence techniques rather than Newton Raphson. Prasanthi and Hazeena [4], used PSO and improved PSO techniques in finding the optimal power flow by putting the power loss function as the problem objective. Four decisions variables were taken in order to minimize the power loss; power generated from generating plants, specified voltage magnitude at control substations, tap positions of tap changing transformers and reactive power injection from reactive power compensators. The idea was applied on 30-bus IEEE test system. Finally the last conclusion was, IPSO gives the minimum power loss

Others discussed different artificial intelligence optimization techniques to minimize active power loss such as Altaf et. al. [5] controlling the flow of reactive power and the last (reactive power) can be controlled through the generator bus voltage, transformer tappings and shunt capacitor banks.

Furthermore, Numphetch et. al.[6], used the power transmission loss as the objective function. They described and compared different method in solving the problem of power flow such as Genetic Algorithm (GA), Particle Swarm Optimization (PSO), Artificial Bee Colony (ABC) and Differential Evolution (DE). A 6-bus and 30-bus IEEE power systems were used for test. Finally the conclusion was the $\mathrm{ABC}$ and $\mathrm{DE}$ provide better results than other swarm intelligent techniques

This paper uses particle swarm optimization (PSO) and weighted particle swarm optimization (WPSO) in minimizing the power loss. The procedure is applied on 30-bus IEEE test system. The rest of the paper is organized as follows: section 2 describes the concept of series and shunt compensators. The problem formulation, objective function and constraints are illustrated in section 3. The pseudo codes of PSO and WPSO are presented in section 4 while the simulated results are discussed in section 5. Conclusion remarks are in the last section.

\section{CONCEPT OF SERIES AND SHUNT COMPENSATORS}

Active and reactive power can be controlled by controlling the overall line impedance, voltage and phase angle. And this can be made by series and shunt compensations [7]. 


\subsection{Series Compensation:}

Series compensation is a capacitor connected in series with the transmission line in order to control the line impedance. Fig. 1 shows a simplified model of a transmission system with series compensation. The two buses are assumed to have the same voltage $\mathrm{V}$ and the phase angle between them is $\delta . \mathrm{X}_{\mathrm{L}}$ is the reactance of the transmission line. $\mathrm{C}$ is the series connected capacitor [1].

Defining $X_{C}$ as part of $X_{L}$

$\mathrm{X}_{\mathrm{C}}=\mathrm{A} \mathrm{X}_{\mathrm{L}}$

A is constant from $(0-1)$

The overall series inductance will be

$X=X_{C}-X_{L}=X_{L}-A X_{L}=(1-A) X_{L}$

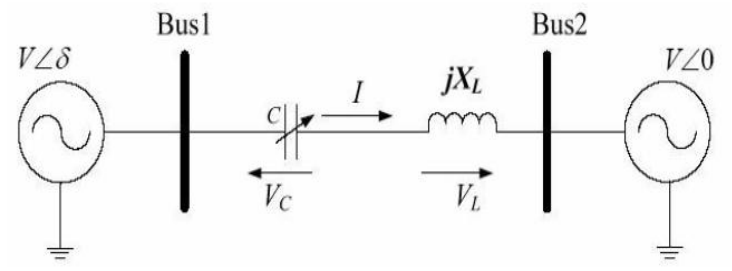

Fig 1: Transmission system with series compensation

\subsection{Shunt Compensation:}

Shunt compensation used to reduce the unwanted reactive power and to regulate the voltage magnitude. As a result shunt compensation helps the system to minimize its losses and enhance its voltage stability.

Fig 2 shows a simple transmission system model with two buses. These two buses have the same voltage $\mathrm{V}$ and the phase angle between them is $\delta$. The transmission line is assumed lossless, $\mathrm{X}_{\mathrm{L}}$ is the inductive reactance of it. $\mathrm{C}$ is a controlled capacitor connected in parallel at the midpoint of the transmission line.

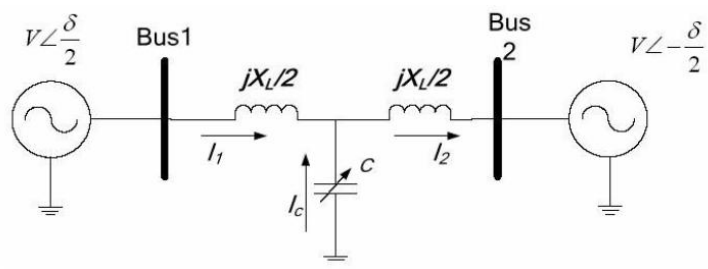

Fig. 2: Transmission system with shunt compensation

By taking the $\pi$ equivalent circuit for the transmission line the shunt capacitor $\left(\mathrm{X}_{\mathrm{C}}\right)$ will be in parallel with the charging admittance $\left(\mathrm{y}_{\mathrm{ch}}\right)$.

In order to make use of the properties of admittance reduction, we will take the reciprocal of $\mathrm{X}_{\mathrm{C}}$ to get $\mathrm{y}_{\mathrm{C}}$ then;

$$
\begin{aligned}
& \mathrm{y}_{\text {at the bus }}=\mathrm{y}_{\mathrm{ch}}+\mathrm{y}_{\mathrm{c}} \\
& \text { Defining } \mathrm{y}_{\mathrm{c}}=\mathrm{A} \mathrm{y}_{\mathrm{ch}} \\
& \mathrm{y}_{\text {at the bus }}=\mathrm{y}_{\mathrm{ch}}+\mathrm{A}_{\mathrm{C}}=(1+\mathrm{A}) \mathrm{y}_{\mathrm{ch}}
\end{aligned}
$$

where A will be constant (0-1) and this will bound the value of the additional capacitor with the system limits.

\subsection{Compound Compensation}

Here two capacitors will be added to the system and the two equations $(2 \& 4)$ will be used in the analysis.

After adding the capacitors new bus admittance matrix ( $\left.\mathrm{Y}_{\text {bus }}\right)$ will be calculated then the analysis of PSO \& WPSO will be started.

\section{PROBLEM FORMULATION}

In general the expression of optimal power flow can be described as a constrained optimization problem as:

\section{Minimize $\mathrm{f}(\mathrm{x})$}

Subject to $g(x)=0$, equality constraints

$\mathrm{h}(\mathrm{x}) \leq 0$, inequality constraints

\subsection{Objective Function}

Some authors took the fuel cost of the generation as the objective function others took reactive power minimization as an objective function. Here the paper is focusing on the minimization of power loss, therefore the objective function will be [6]:

$$
\mathrm{F}_{\text {loss }}=\sum_{\mathrm{i}=1}^{\mathrm{NL}} \mathrm{G}_{\mathrm{ij}}\left\{\mathrm{V}_{\mathrm{i}}^{2}+\mathrm{V}_{\mathrm{j}}^{2}-2 \mathrm{~V}_{\mathrm{i}} \mathrm{V}_{\mathrm{j}} \cos \left(\delta_{\mathrm{i}}-\delta_{\mathrm{j}}\right)\right\}
$$

where

$\mathrm{V}_{\mathrm{i}} \& \mathrm{~V}_{\mathrm{j}}$ : are the voltage magnitudes at bus $\mathrm{i} \&$ bus $\mathrm{j}$ respectively.

$\mathrm{G}_{\mathrm{ij}}$ : is the conductance of line $\mathrm{i}-\mathrm{j}$

$\delta_{i} \& \delta_{j}$ :are the voltage angles at bus $i \&$ bus $j$ respectively.

$\mathrm{N}_{\mathrm{L}}$ : is the total number of transmission lines.

$\mathrm{F}_{\text {loss }}$ : is the power loss function

\subsection{Constraints}

The system can be controlled by the following quantities: voltage magnitude, generator MW, reactive power injection from reactive power sources and transformer tapping [6].

\subsubsection{Equality Constraints:}

Equality constraints are the power flow equations

$$
\mathrm{PG}_{\mathrm{i}}-\mathrm{PD}_{\mathrm{i}}-\sum_{\mathrm{j}=1}^{\mathrm{N}_{\mathrm{B}}}\left|\mathrm{V}_{\mathrm{i}}\right|\left|\mathrm{V}_{\mathrm{j}}\right|\left|\mathrm{Y}_{\mathrm{ij}}\right| \cos \left(\theta_{\mathrm{ij}}-\delta_{\mathrm{i}}+\delta_{\mathrm{j}}\right)=0
$$

$$
\mathrm{QG}_{\mathrm{i}}-\mathrm{QD}_{\mathrm{i}}-\sum_{\mathrm{j}=1}^{\mathrm{N}_{\mathrm{B}}}\left|\mathrm{V}_{\mathrm{i}}\right|\left|\mathrm{V}_{\mathrm{j}}\right|\left|\mathrm{Y}_{\mathrm{ij}}\right| \sin \left(\theta_{\mathrm{ij}}-\delta_{\mathrm{i}}+\delta_{\mathrm{j}}\right)=0
$$

where

$\mathrm{PG}_{\mathrm{i}}$ : is the real power generation at bus $\mathrm{i}$

$\mathrm{QG}_{\mathrm{i}}$ : is the reactive power generation at bus $\mathrm{i}$

$\mathrm{PD}_{\mathrm{i}}$ : is the real power demand at bus $\mathrm{i}$

$\mathrm{QD}_{\mathrm{i}}$ : is the reactive power demand at bus $\mathrm{i}$

$\mathrm{N}_{\mathrm{B}}$ : number of buses.

$\theta_{\mathrm{ij}}$ : is the angle of bus admittance element ij

$\mathrm{Y}:$ is the bus admittance matrix

$\mathrm{Y}_{\mathrm{ij}}$ : is the magnitude of bus admittance element $\mathrm{ij}$. 


\subsubsection{Inequality Constraints:}

Limits for each variable [6],

$$
\begin{aligned}
& \mathrm{V}_{\mathrm{i}}^{\text {min }} \leq \mathrm{V}_{\mathrm{i}} \leq \mathrm{V}_{\mathrm{i}}^{\max } \\
& \mathrm{T}_{\mathrm{i}}^{\min } \leq \mathrm{T}_{\mathrm{i}} \leq \mathrm{T}_{\mathrm{i}}^{\max } \\
& \mathrm{Q}_{\text {comp }, \mathrm{i}}^{\min } \leq \mathrm{Q}_{\text {comp,i }} \leq \mathrm{Q}_{\text {comp }, \mathrm{i}}^{\max } \\
& \mathrm{PG}_{\mathrm{i}}^{\min } \leq \mathrm{PG}_{\mathrm{i}} \leq \mathrm{PG}_{\mathrm{i}}^{\max }
\end{aligned}
$$

where:

$\mathrm{V}_{\mathrm{i}}^{\min }, \mathrm{V}_{\mathrm{i}}^{\max }$ : are the upper and lower limits of voltage magnitude at bus $i$

$\mathrm{T}_{\mathrm{i}}^{\mathrm{min}}, \mathrm{T}_{\mathrm{i}}^{\mathrm{max}}:$ are the upper and lower limits of tap position of transformer i

$\mathrm{Q}_{\text {comp,i }}^{\min }, \mathrm{Q}_{\text {comp,i }}^{\max }:$ are the upper and lower limits of reactive power source $i$.

$P G_{i}^{\min }, P_{i}^{\max }$ : are the upper and lower limits of power generated by generator $\mathrm{i}$.

\section{OPTIMIZATION METHODS:}

\subsection{Standard PSO:}

PSO is a particle swarm optimization was first developed and presented by Kennedy and Eberhat [8]. It is based on the movement and behavior of individuals (particles) of the swarm such as birds flock, fish flock or insects colony [12]. PSO needs at least 25 particles and begins from random initial values then check if these values will satisfy the target (objective function) or not. In case of not satisfying the target, an updating in velocity and position will occur and a new iteration will begin. In case of satisfying the objective function the program will stop.

The equations for PSO are summarized below and the pseudo code is presented in Fig. 3.

At the beginning the position and velocity for each particle will be

$$
\begin{gathered}
\mathrm{x}_{\mathrm{i}}^{0}=\mathrm{K}^{\mathrm{min}}+\left(\mathrm{K}^{\mathrm{max}}-\mathrm{K}^{\mathrm{min}}\right) * \operatorname{rand}_{\mathrm{i}} \\
\mathrm{v}_{\mathrm{i}}^{0}=\frac{\mathrm{x}_{\mathrm{i}}^{0}}{2}
\end{gathered}
$$

The velocity and position will be updated as follows:

\begin{tabular}{|c|c|}
\hline$v_{i, m}^{t+1}:$ & Modified velocity of particle $i$. \\
\hline$w:$ & Inertia of the previous velocity. \\
\hline$c_{1} \& c_{2}:$ & Acceleration constants. \\
\hline $\operatorname{rand}_{1} \& \operatorname{rand}_{2}$ & $\begin{array}{l}\text { Uniformly generated random numbers in the } \\
\text { range of }[0,1] .\end{array}$ \\
\hline$x_{i, m}^{t}:$ & Current position of particle $i$ at iteration $t$. \\
\hline$x_{i, m}^{t+1}$ & Modified position of particle i. \\
\hline$\Delta t:$ & Time step which is taken to be unity. \\
\hline$P_{\text {best } i, m}:$ & $\begin{array}{l}\text { The best previous position along the } \mathrm{m}^{\text {th }} \\
\text { dimension of particle } \mathrm{i} \text { in iteration } \mathrm{t} \text {. }\end{array}$ \\
\hline$g_{\text {best } m}:$ & $\begin{array}{l}\text { The best previous position among all the } \\
\text { particles along the } \mathrm{m}^{\text {th }} \text { dimensionin iteration } \mathrm{t} \text {. }\end{array}$ \\
\hline
\end{tabular}

$$
\begin{aligned}
v_{\mathrm{i}, \mathrm{m}}^{\mathrm{t}+1}=\mathrm{w} \mathrm{v}_{\mathrm{i}, \mathrm{m}}^{\mathrm{t}}+ & \mathrm{c}_{1} \operatorname{rand}_{1} *\left(\mathrm{P}_{\text {best } \mathrm{i}, \mathrm{m}}-\mathrm{x}_{\mathrm{i}, \mathrm{m}}^{\mathrm{t}}\right) \\
& +\mathrm{c}_{2} \operatorname{rand}_{2} *\left(\text { g gest } \mathrm{m}_{\text {bes }}-\mathrm{x}_{\mathrm{i}, \mathrm{m}}^{\mathrm{t}}\right)
\end{aligned}
$$$$
\mathbf{x}_{\mathrm{i}, \mathrm{m}}^{\mathrm{t}+\mathbf{1}}=\mathbf{x}_{\mathrm{i}, \mathrm{m}}^{\mathrm{t}}+\Delta \mathbf{t} \mathbf{v}_{\mathrm{i}, \mathrm{m}}^{\mathrm{t}+1}
$$

where,

$$
\begin{array}{ll}
i=1,2, \ldots \ldots, n \text { and } m=1,2, \ldots \ldots, d ; \\
n: & \text { Population size. } \\
d: & \text { Search space dimension. } \\
t: & \text { Current iteration. } \\
v_{i, m}^{t}: & \text { Current velocity of particle i at iteration t. }
\end{array}
$$

The cognitive and social acceleration factors $c_{1} \& c_{2}$ respectively are chosen to be 1.494 and the inertial weight $\mathrm{w}$ to be 0.729 as recommended in Clerc's PSO [9].

\section{Step 1. Start}

Step 2. Create an initial swarm; the swarm consists of 25 particles, each particle has a position and a velocity. Here the position will be the voltage from $0.95-1.06$ p.u.

Step 3. Evaluate the fitness for each particle to get the first pbest and gbest according to Eq.(5).

Step 4. Updating the position and the velocity for each particle with constant weight (0.7), Eq.s (10 \&11).

Step 5. Evaluate the fitness for each particle to get the new pbest and gbest.

Step 6. Check the stopping criterion (minimum power loss); if the results are satisfied the stopping criterion go to step 8. If the results didn't satisfy the stopping criterion go to step 7 .

Step 7. Update the position and the velocity, increase the iteration counter Iter $=$ Iter +1 and go to step3

Step 8. Obtain pbest and gbest.

Step 9. End

Fig. 3: Pseudo code of PSO algorithm.

\subsection{Weighted PSO:}

The general description of WPSO is the same as PSO, the difference is in the factor $w$. The weight was fixed at 0.7 in PSO algorithm while it will be varied as in Eq. (12 ) in WPSO [10].

$$
\begin{aligned}
& \mathrm{w}= \\
& \begin{cases}\mathrm{w}_{\text {min }}+\frac{\left(\mathrm{w}_{\text {max }}-\mathrm{w}_{\text {min }}\right)\left(\mathrm{f}-\mathrm{f}_{\text {min }}\right)}{\mathrm{f}_{\text {avg. }}-\mathrm{f}_{\text {min }}}, \mathrm{f} \leq \mathrm{f}_{\text {avg. }} \\
\mathrm{w}_{\text {max }}, \mathrm{f}>\mathrm{f}_{\text {avg. }}\end{cases}
\end{aligned}
$$

where:

$\mathrm{w}_{\max }$ and $\mathrm{w}_{\min }$ : represents the maximum and minimum of $\mathrm{w}$ respectively.

In this paper $\mathrm{w}_{\max }=0.9$ while $\mathrm{w}_{\min }=0.4$

$\mathrm{f}:$ is the current objective value of the particle. 
$f_{\text {avg. }}:$ is the average objective value of all particles.

$\mathrm{f}_{\min } .:$ is the minimum objective value of all particles.

\section{Step 1. Start \\ Step 2. Create an initial swarm; the swarm consists of 25 particles, each particle has a position and a velocity. Here the position will be the voltage from $0.95-1.06$ p.u.}

Step 3. Evaluate the fitness for each particle to get the first pbest and gbest according to Eq.(5).

Step 4. Updating the position and the velocity (Eq.s $(10 \& 11)$ for each particle with variable weight as in Eq.(12)

Step 5. Evaluate the fitness for each particle to get the new pbest and gbest.

Step 6. Check the stopping criterion (minimum power loss); if the results satisfied the stopping criterion go to step 8 . If the results didn't satisfy the stopping criterion go to step 7 .

Step 7. Update the position and the velocity, increase the iteration counter Iter $=$ Iter +1 and go to step3

Step 8. Obtain pbest and gbest.

Step 9. End

Fig. 4: Pseudo code of WPSO algorithm

\section{RESULTS AND DISCUSSION:}

The procedure is applied on IEEE 30-bus test system [11]. The single line diagram for this system is shown in Fig. 5. The system consists from 41 transmission line, 24 load bus, and 6 generator bus (on buses: 1, 2, 5, 8, 11 and 13), bus number 1 is recommended to be the slack bus. PSO and WPSO algorithms are used in analyzing the system via MATLAB R2013a environment and run on Intel core i5, 2.4GHz, 4GB. Fig. 6, illustrates the cases of this work; at the beginning the system is analyzed with light load (without any increasing in load), with nominal load (50\% increasing in load on bus 12) and with heavy load (50\% increasing in load on bus 12 and bus 20) without compensation then with series and compound compensations.

Without compensation, WPSO gives less power loss than PSO in nominal and heavy loads as shown in Fig.7.

Talking about series compensation; Table-I, illustrates the power loss for all the suggested lines and all the suggested capacitor values in case"d" with PSO and WPSO. In this case there are 5 lines $(4-12,12-13,12-14,12-5$, and 12-16) and one capacitor will be added in series with each line, each time the program is executed new value of Ploss will be gotten. It is clear from the table that the minimum power loss occurs at line 12-14 with $A=0.5$ in PSO while it occurs at line 12-13 with $A=0.1$ in WPSO. In spite of the minimum values of Ploss are the same in the two algorithms, WPSO is better than PSO. That because the program is reached to the same power with less value of capacitor and the reactive power will be less with WPSO as shown in Fig.8.

In compound compensation two capacitors are needed one is connected in series with the transmission line and the other is connected in parallel with the bus. Fig.s (9\&10) demonstrate the minimum Ploss at each case.

In spite of WPSO and PSO reached to the same value of Ploss with different places of the parallel capacitor as it can be seen in Figs. (9\&10), WPSO works better than PSO in heavy loads. That because the reactive power in WPSO will be less than that in PSO as shown in Fig. 11.

\section{$\underline{\text { Case study }}$ \\ case a \\ System alone (without increasing in load and without any compensation).}

case b:

System with $50 \%$ increasing in load on bus 12 without any compensation.

case c :

System with $50 \%$ increasing in load on bus $12 \&$ bus 20 without any compensation.

case d:

System with $50 \%$ increasing in load on bus 12 with series compensation. (a capacitor is connected in series with lines 4-12, 12-13, 12-14, $12-15,12-16)$

$\underline{\underline{\text { case e : }}}$

System with $50 \%$ increasing in load on bus 12 \& bus 20 with series compensation. (a capacitor is connected in series with lines4-12, 12-13, 12-14, $12-15,12-16,19-20,10-20)$.

case f:

System with 50\% increasing in load on bus 12 with compound compensation. (one capacitor is connected in series with lines $4-12,12-13,12-14$, $12-15,12-16$ \&another one is connected in parallel with bus 12)

case $\mathrm{g}$ :

System with $50 \%$ increasing in load on bus $12 \&$ bus 20 with compound compensation. (one capacitor is connected in series with lines 4-12, $12-13,12-14,12-15,12-16,19-20,10-20 \&$ another one is connected in parallel with bus 12 ).

case h:

System with $50 \%$ increasing in load on bus $12 \&$ bus 20 with compound compensation. (one capacitor is connected in series with lines 4-12, $12-13,12-14,12-15,12-16,19-20,10-20$ \&another one is connected in parallel with bus 20).

Fig. 6: Case study 
Table I: Power loss with series compensation in case of $50 \%$ increasing in load on bus 12

\begin{tabular}{|c|c|c|c|}
\hline line & Ploss with PSO & Ploss with WPSO & A \\
\hline $4-12$ & $0.6412 * 10-15$ & $13.77 * 10-15$ & 0.1 \\
\hline $4-12$ & 0.0739 & $1.122 * 10-15$ & 0.5 \\
\hline $4-12$ & $1.115 * 10-15$ & $3.52 * 10-8$ & 0.8 \\
\hline $12-13$ & 0.237 & $0.54 * 10-15$ & 0.1 \\
\hline $12-13$ & 0.3329 & $1.49 * 10-15$ & 0.5 \\
\hline $12-13$ & $1.25 * 10-15$ & $18.277 * 10-15$ & 0.8 \\
\hline $12-14$ & $1.115 * 10-15$ & $31.422 * 10-15$ & 0.1 \\
\hline $12-14$ & $0.54 * 10-15$ & $3.007 * 10-15$ & 0.5 \\
\hline $12-14$ & 0.489 & $1.125 * 10-15$ & 0.8 \\
\hline $12-15$ & $3.04 * 10-15$ & $6.09 * 10-15$ & 0.1 \\
\hline $12-15$ & $3.046 * 10-15$ & $6.13 * 10-13$ & 0.5 \\
\hline $12-15$ & $0.6412 * 10-15$ & $3.38 * 10-11$ & 0.8 \\
\hline $12-16$ & 0.0906 & 0.546 & 0.1 \\
\hline $12-16$ & 0.3713 & $1.302 * 10-13$ & 0.5 \\
\hline $12-16$ & 0.422 & $1.252 * 10-15$ & 0.8 \\
\hline
\end{tabular}

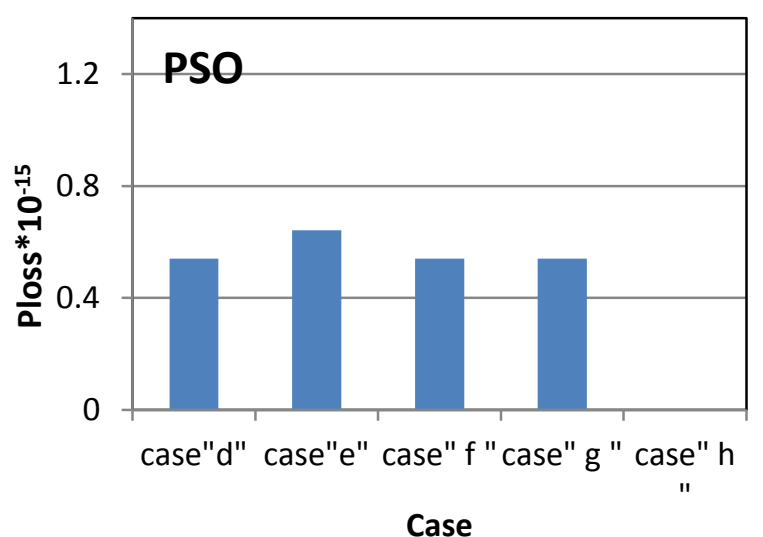

Fig. 9: The best Ploss for each case using PSO

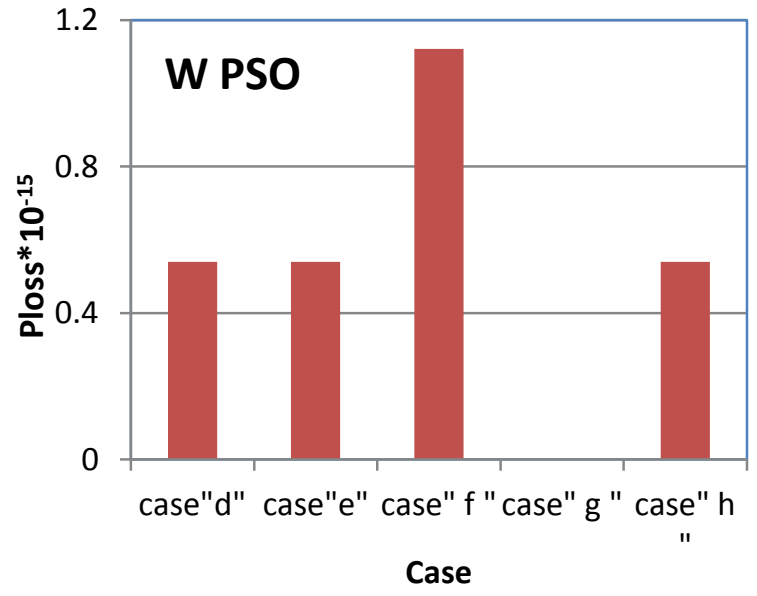

Fig. 10: The best Ploss for each case using WPSO

\section{CONCLUSION}

Many researchers presented and discussed different methods of artificial intelligent to minimize the power loss. This paper focused on finding the optimal placement of series and compound compensators to minimize power loss and to enhance voltage stability profile. The procedure is based on PSO and Weighted PSO algorithms. After simulation the paper concludes that the results in WPSO are better than that in PSO especially with heavy load case. Both power loss and reactive power will be less. Also the optimal placement was done by changing the value and place of the compensated capacitor or capacitors that is/are connected in series or in parallel. In nominal load despite reaching to the same value of power loss WPSO is better than PSO, because the reactive power is less also. Moreover the simulation procedure is applicable on more or less than 30-bus power system.

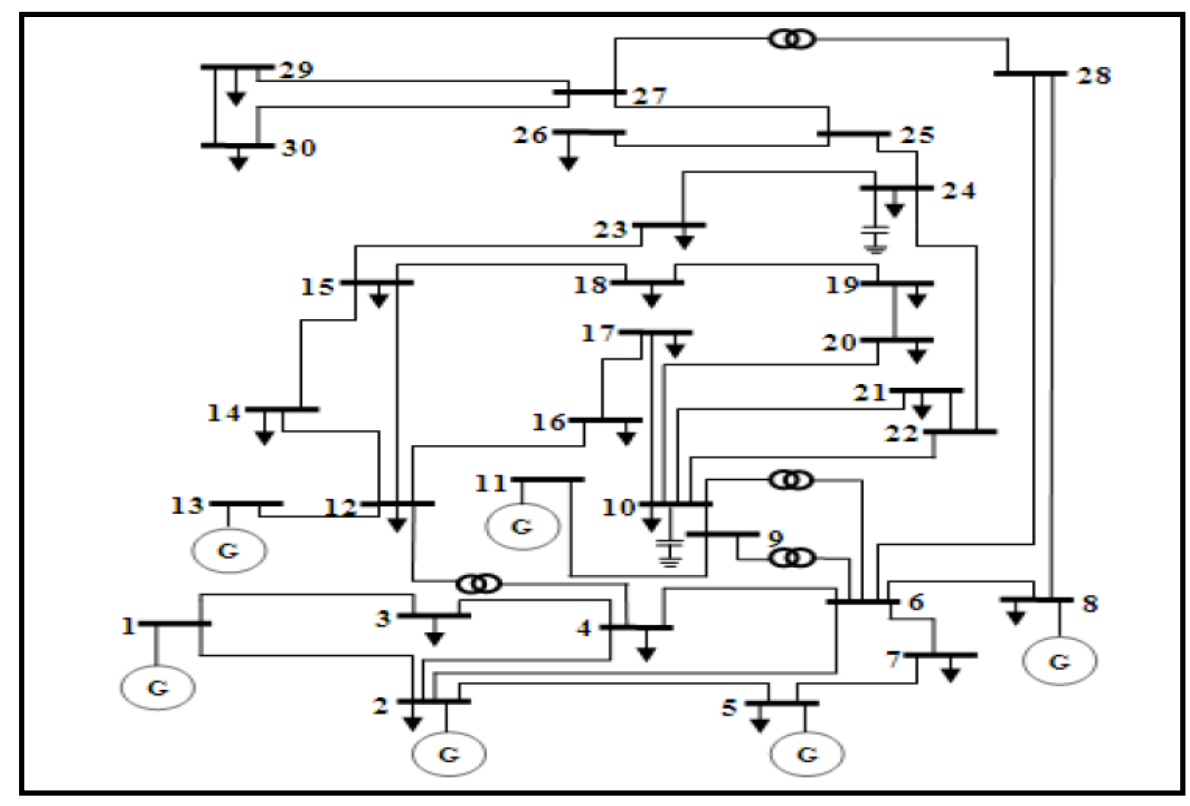

Fig. 5: Single line diagram of IEEE 30-bus test system 


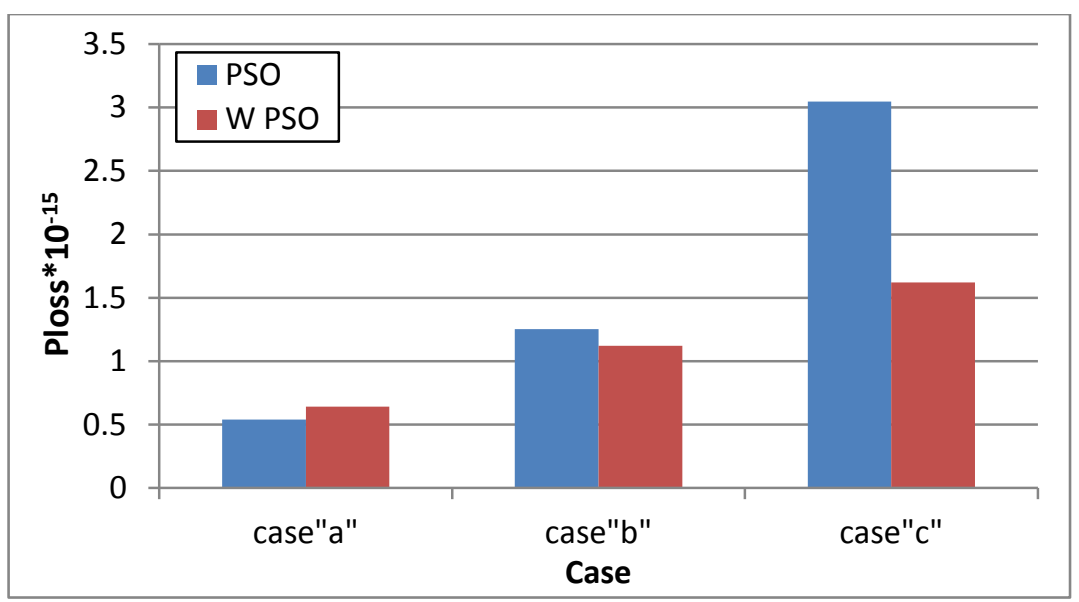

Fig. 7: Comparison between PSO \& WPSO for the system with light, nominal and heavy loads without any compensation.

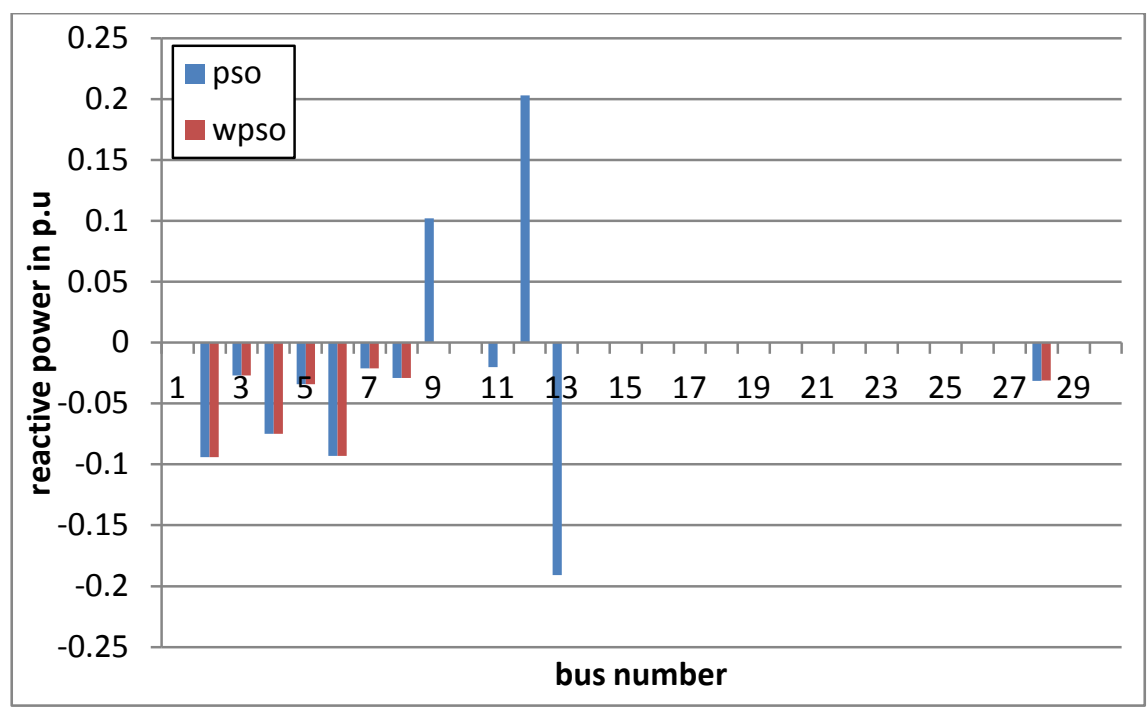

Fig. 8: Reactive power with PSO and WPSO for case "d"

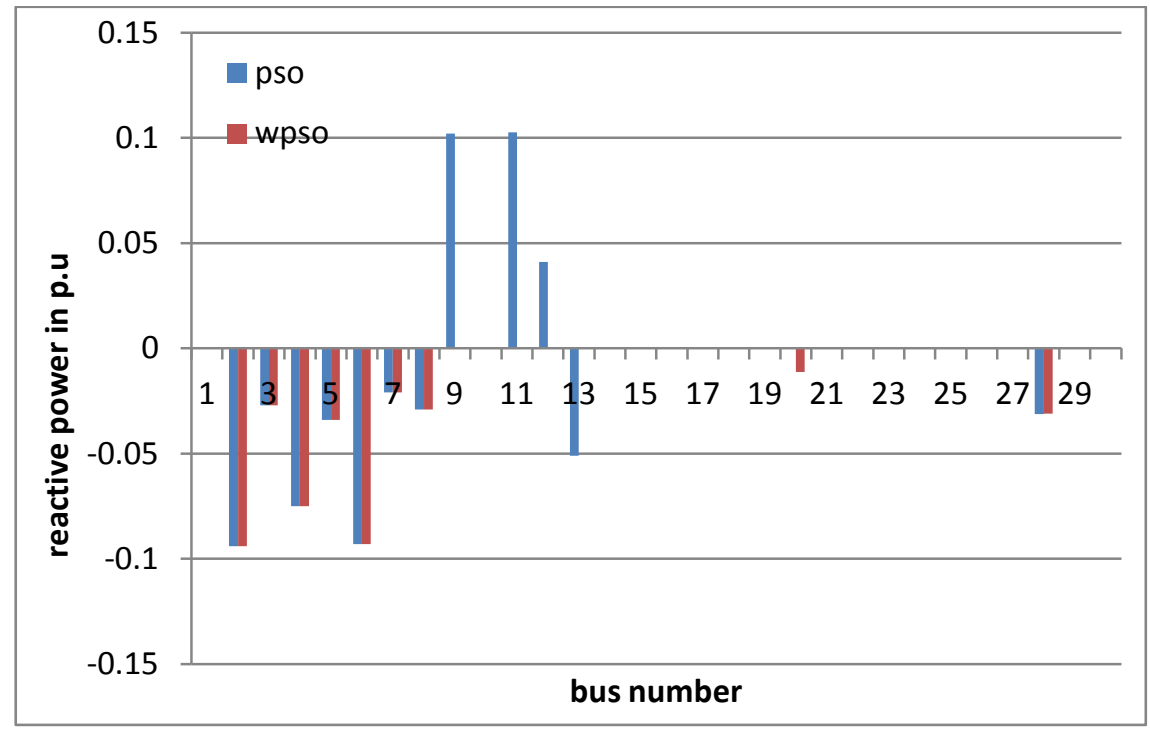

Fig. 11: Reactive power in p.u at each bus with PSO \& WPSO for the minimum power loss in compound case. 


\section{REFERENCES}

[1] Hasan Dağ, Banu Öztürk and Aysu Özyürek, "Application of series and shunt compensation to Turkish national power transmission system to improve system load ability", ELECO99 international conference on electrical and electronics engineering (Eo1.101/A261),1999, pp.243-247.

[2] Ulas Eminoglu, M. Hakan Hocaoglu and Tankut Yalcinoz, "Transmission line shunt and series compensation with voltage sensitive loads", International Journal of Electrical Engineering Education 46/4,2009, pp:354-369,

[3] Om Prakash Mahela\& Sheesh Ram Ola, "Comparison of HT Shunt Capacitors and SVC for Active and Reactive Power Flow Control in Transmission Line: the Case of RRVPNL Power Grid", International Journal of Electrical and Electronics Engineering (IJEEE), ISSN 2278-9944, Vol. 2, Issue 1, Feb 2013,pp: 49-58

[4] Prasanthi P. S, Hazeena K .A ,"Improved Particle Swarm Optimization Based Loss Minimization", International Journal of Advanced Research in Electrical, Electronics and Instrumentation Engineering, Vol. 2, Special Issue 1, December 2013, ISSN (Print) : 2320 - 3765, ISSN (Online): 2278 - 8875, pp: 21-29. India.

[5] Altaf Badar, Dr. B.S. Umre, and Dr. A. S. Junghare, "Study of Artificial Intelligence Optimization Techniques applied to Active Power Loss Minimization", IOSR Journal of Electrical and Electronics Engineering (IOSR-JEEE) e-ISSN: 2278-1676, p-ISSN: 2320-3331 PP 39-45 www.iosrjournals.org.

International Conference on Advances in Engineering \& Technology - 2014 (ICAET-2014)
[6] Numphetch Sinsuphun, Uthen Leeton, Umaporn Kwannetr, "Loss Minimization Using Optimal Power Flow Based on Swarm Intelligences", ECTI Transactions on Electrical Eng., Electronics, and Communications Vol.9, NO.1 February 2011, pp:212-222.

[7] Xiao-Ping Zhang, Christian Rehtanz and Biksh Pal, "Flexible AC transmission systems modeling and control ", springer-verlag Berlin Heidelberg 2006. Printed in Germany.

[8] Kennedy, J. and R. Eberhart, \Particle swarm optimization," IEEE Proc. International Conference on Neural Networks, 1942-1948, Perth, Aust, November 1995.

[9] M. Clerc, "The Swarm and the Queen: Towards a Deterministic and Adaptive Particle Swarm Optimization", Proceedings of Congress on Evolutionary Computation, Annecy, France, vol. 3, pp. 1951-1957, 06-09 July, 1999.

[10] Chai, J. Li, Y. Zhang, M. Jiang, and Y. Xu, "Intelligent Optimization Method of PSS Parameters Based on Grid Equivalence", International Conference on Electrical and Control Engineering (ICECE), Yichang, China, 16-18 Sept. 2011.

[11] R. Zimmerman, C. E. Murillo-Sanchez, and D. Gan, "MATPOWER: A MATLAB power system simulation package", Cornell University, Ithaca, NY, 2008. [Online]. Available: http://www.pserc.cornell.edu/matpower/

[12] S J Bassi, M K Mishra and E E Omizegba, Automatic Tuning of Proportional-Integral-Derivative (PID) Controller using Particle Swarm Optimization (PSO) Algorithm. International Journal of Artificial Intelligence \& Applications (IJAIA), 2011.vol.2, no.4, pp:25-34. 